\title{
REVIEW
}

\section{Erectile dysfunction and the cardiovascular patient: endothelial dysfunction is the common denominator}

\section{H Solomon, J W Man, G Jackson}

Heart 2003;89:251-254

Erectile dysfunction (ED) is a common condition and studies predict that it will become even more common in the future. There is increasing evidence to suggest that it is predominantly a vascular disease and may even be a marker for occult cardiovascular disease. The common pathological process is at the level of the endothelium, and cardiovascular risk factor control may be the key to preventing ED. Many men with established cardiovascular disease have ED. Specific guidelines for the management of $E D$ in these patients have been produced by an expert panel. Cardiovascular risk stratification is an important initial step in managing such patients. In cardiac patients considered to have low cardiovascular risk, the management of ED can be safe and effective.

See end of article for authors' affiliations

\section{Dr G Jackson, Department} of Cardiology, 6th Floor, East Wing, St Thomas' Hospital, Lambeth Palace Road, London SE 1 7EH, UK; a.cooper@ cardiocentre.u-net.com

Accepted 12 June 2002
$\mathrm{E}$ rectile dysfunction (ED) is defined as the inability to achieve and maintain an erection sufficient to permit satisfactory sexual intercourse. ${ }^{1}$ It was estimated that in 1995, ED affected over 152 million men worldwide. The projection for 2025 is a prevalence of 322 million men worldwide with the largest projected increases in the developing world-that is, Africa, Asia, and South America. ${ }^{2}$ The incidence and severity of ED are well documented to increase with age: a man aged 70 years is three times more likely to have ED than a man aged 40 years. ${ }^{3}$ The increased prevalence of risk factors for ED (for example, hypertension, vascular disease, and benign prostatic hypertrophy) among the elder population rather than the aging process itself seems to be responsible for the age related association.

One of the most difficult hurdles for many men is admitting that they have a problem. The stigma associated with ED prevents men from seeking help. Sexual health is an important component of overall wellbeing. Many men with ED have low self esteem and feel isolated because they are unable to discuss this sensitive issue with their physician for fear of embarrassment. Evidence has shown that ED has a significant negative impact on quality of life measures ${ }^{4}$ and that the successful treatment of ED is associated with significant improvements of overall and emotional wellbeing.

The likely worldwide increase in the prevalence of ED and the social stigma attached to the condition present a serious challenge for health care policy makers to develop and implement measures to manage ED. However, one of the most significant advances in the field of research for ED is the recent increasing awareness of its high prevalence among men with cardiovascular disease. An emphasis on this strong correlation with cardiovascular disease would not only open the door to men to admit more freely to having ED, but would also bring about opportunities for health care systems to address the increasing prevalence of this distressing condition through cardiovascular risk assessment. This article focuses on the relation between the cardiovascular patient and ED and outlines management strategies for treating ED in the cardiovascular patient.

\section{PHYSIOLOGY AND PATHOPHYSIOLOGY OF ED}

Penile erection is a neurovascular event modulated by psychological and hormonal factors. ${ }^{6}$ On sexual stimulation, an increase in parasympathetic activity causes the release of neurotransmitters from the cavernous nerve terminals and of relaxing factors from the endothelial cells in the penis. This results in smooth muscle relaxation in the arteries and arterioles supplying the erectile tissue and a severalfold increase in blood flow to the penis. Venous outflow from the penis is simultaneously occluded. These events allow the penis to become erect with an intracavernosal pressure of approximately $100 \mathrm{~mm} \mathrm{Hg}$. Smooth muscle relaxation is brought about by the release of nitric oxide from both the endothelial cells and neural tissue supplying the corpora cavernosa. Nitric oxide activates a soluble guanylyl cyclase, which raises the intracellular concentration of cyclic GMP. Cyclic GMP in turn activates a specific protein kinase, which ultimately blocks calcium influx by inhibition of calcium channels. This causes a drop in cytosolic calcium concentrations and results in relaxation of smooth muscle (fig 1).

Thus, disturbances in the basic neurovascular event or the modulating factors that control this event (psychological or hormonal) may be responsible for ED. The aetiology of ED is generally classified as psychological, physiological (neurogenic, hormonal, vascular, cavernosal, or drug induced), or mixed.

Psychological factors include performance anxiety, depression, and psychosocial stress. It must be emphasised that cause and effect can be difficult to ascertain and that psychosexual counselling is usually the treatment of choice.

Physiological factors are a more common aetiology and neurological disorders such as Parkinson's disease, multiple sclerosis, and spinal cord disorders are all well documented to cause ED. ${ }^{7}$ In addition, hormonal disorders such as hypogonadism and hyperprolactinaemia are known to cause ED, as are local causes such as carcinoma of the prostate or disorders of the penis itself. However, 


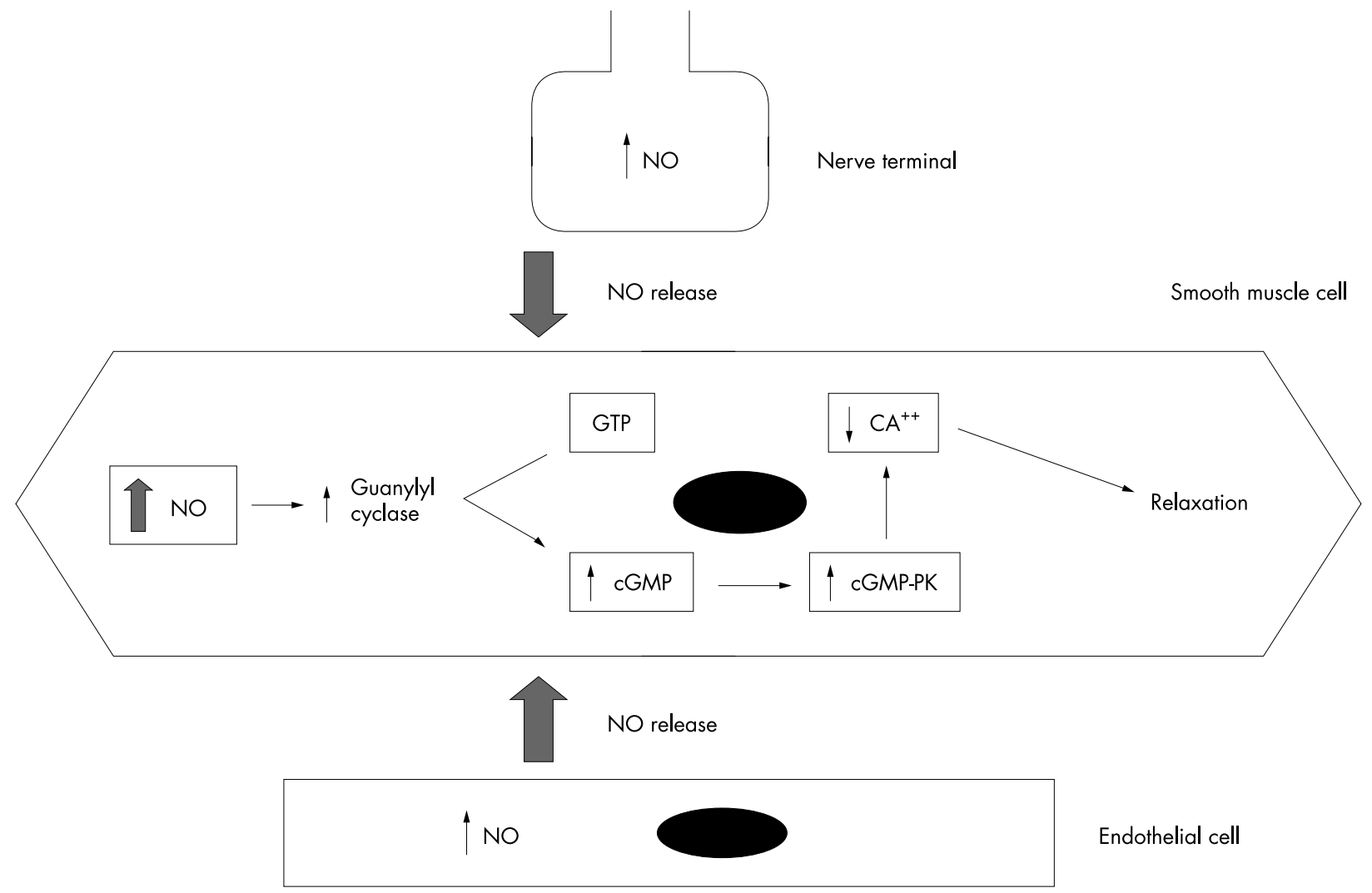

Figure 1 Mechanisms involved in smooth muscle cell relaxation in the corpus cavernosum. GMP, guanosine monophosphate; GTP, guanosine triphospate; NO, nitric oxide; PK, protein kinase.

vascular disorders such as diabetes, hypertension, and hyperlipidaemia tend to be the most common culprits.

\section{ED AND CARDIOVASCULAR DISEASE}

The MMAS (Massachusetts male aging study), a large population based random sample, confirmed that ED is highly correlated with vascular diseases such as hypertension, heart disease, and diabetes. ${ }^{3}$ Patients who were being treated for hypertension had a $15 \%$ probability of complete ED and those who had cardiac disease had a probability of $39 \%$. This probability increased to $20 \%$ for hypertensive men who smoked cigarettes and to $56 \%$ for cardiac patients who smoked. The association between ED and hypercholesterolaemia has also been documented in a group of healthy men complaining of ED, with over $60 \%$ having abnormal cholesterol concentrations and over $90 \%$ of these showing evidence of penile arterial disease on Doppler ultrasound testing. ${ }^{8}$ Diabetes has been associated with an increased risk of ED. The prevalence is approximately $50 \%$, with a range of $27.5-59 \%$ depending on age and disease severity. Other studies have shown that atherosclerosis is associated with almost $40 \%$ of cases of ED in men aged 50 years or more. ${ }^{9}$ Recently, Bortolotti and colleagues analysed four studies involving 1476 men with heart disease, myocardial infarction or vascular surgery. ${ }^{10}$ They found incidences of ED ranging from 39-64\% in each patient group.

ED and vascular disease are thought to be linked at the level of the endothelium. Endothelial dysfunction results in an inability of the smooth muscle cells lining the arterioles to relax, thus preventing vasodilatation. Diabetic men with ED infused with L-arginine were found to have a lower reduction in blood pressure and platelet aggregation response (markers of endothelial function) than that in diabetic men without ED. Hence, the endothelial response was significantly reduced in impotent diabetic men ${ }^{11}$ thereby preventing adequate arteriolar vasodilatation and causing ED. Similar findings have been found in conditions of hypercholesterolaemia. Rabbits were fed a cholesterol enriched diet or normal diet (controls) for three months, after which time cavernous tissue biopsies were taken. Ultramorphological examination of the control group found normal smooth muscle cell architecture. The high cholesterol diet group had significant smooth muscle cell degeneration with loss of intercellular contacts. This study suggests that impaired lipid metabolism causes cavernous smooth muscle cell degeneration and plays a major part in the development of ED. ${ }^{12}$

Insults such as these not only damage the endothelium and hence cause ED but they are also precursors for the development of atherosclerosis and coronary artery disease. Indeed, the presence of vasculogenic ED has been suggested as a risk factor for the presence of occult cardiovascular disease. ${ }^{13}$ Pritzker $^{14}$ reviewed the results of cardiovascular stress testing, risk profile analysis, and angiography in 50 asymptomatic men with ED of presumed vascular origin aged between 40-60 years. Multiple cardiovascular risk factors were present in $80 \%$ and graded exercise testing was electrically positive in 28 of 50 men. Coronary angiography in 20 men found left main stem or severe three vessel disease in six, moderate two vessel disease in seven, and significant single vessel disease in a further seven. In addition, other recent work has suggested that erectile function correlates with the severity of cardiovascular disease. Patients with single vessel ischaemic heart disease had less difficulty obtaining an erection than did patients with two or three vessel ischaemic heart disease. ${ }^{15}$

Pharmacological measures to control these vascular risk factors are also associated with the onset of ED. Many antihypertensive medications (particularly $\beta$ blockers and thiazide diuretics) have sexual dysfunction as one of their main side effects, which invariably reduces compliance. ${ }^{16}$ Statin treatment routinely recommended for cardiovascular disease has been related to worsening erectile function. ${ }^{17}$ An association between angiotensin converting enzyme (ACE) inhibitors and 
Table 1 Recommendations for management of erectile dysfunction based on graded cardiovascular risk assessment

\begin{tabular}{|c|c|c|}
\hline Grading of risk & Cardiovascular status on presentation & Management recommendations for the primary care physician \\
\hline Low risk & $\begin{array}{l}\text { - Asymptomatic, <3 major risk factors for CAD, excluding } \\
\text { - } \text { Cone and sex } \\
\text { - Mild stabled hypertension } \\
\text { - Successful coronary } \\
\text { - Mild valve disease } \\
\text { - LVD/CHF (NYHA class I) }\end{array}$ & $\begin{array}{l}\text { - Provide primary care management } \\
\text { - Review treatment options with patient and his partner (where possible) }\end{array}$ \\
\hline Intermediate risk & $\begin{array}{l}\text { - }>3 \text { major risk factors for CAD, excluding age and sex } \\
\text { - Moderate stable angina } \\
\text { Recent myocardial infarction or cardiovascular event } \\
\text { (<6 weeks) } \\
\text { - LVD/CHF (NYHA class II) } \\
\text { - Murmur of unknown cause }\end{array}$ & $\begin{array}{l}\text { - Conduct a specialised evaluation (for example, exercise treadmill test } \\
\text { for angina, echocardiography for murmur) } \\
\text { - Place patient into high or low risk category, depending on outcome } \\
\text { of testing }\end{array}$ \\
\hline High risk & $\begin{array}{l}\text { - Unstable or refractory angina } \\
\text { - Uncontrolled hypertension (SBP >180 mm Hg) } \\
\text { - CHF (NYHA class III, IV) } \\
\text { - Recent myocardial infarction or cardiovascular event } \\
\text { (<2 weeks) } \\
\text { - High risk arrhythmias } \\
\text { - Hypertrophic obstructive and other cardiomyopathies } \\
\text { - Moderate/severe valve disease }\end{array}$ & $\begin{array}{l}\text { - Refer for specialised cardiac evaluation and management } \\
\text { - Defer treatment for erectile dysfunction until cardiac condition } \\
\text { stabilised or specialist evaluation completed }\end{array}$ \\
\hline
\end{tabular}

Reproduced from Jackson and colleagues ${ }^{27}$ with permission. CAD, coronary artery disease; CHF, congestive heart failure; LVD, left ventricular dysfunction; NYHA, New York Heart Association; SBP, systolic blood pressure.

ED has been previously described in a survey of the causes of impotence in 101 men with hypertension, which found a prevalence of $26 \%$. Among those with hypertension, $70 \%$ were taking an ACE inhibitor. ${ }^{18}$ Furthermore, 12 men in this study identified medication as the cause and over $50 \%$ attributed the onset of ED to the ACE inhibitor treatment.

The management of ED remains primarily within the domain of urologists, psychologists, and family practitioners. However, the association of ED with vascular disease has led to the need for other medical specialists, including cardiologists, to become involved in the management of ED. In 1999 the Princeton Consensus Panel, an expert panel comprising cardiologists, urologists, pharmacologists, and psychiatrists, evaluated the scientific evidence on sexual activity and its risk in cardiac patients. $^{19}$

\section{MANAGEMENT OF ED IN PATIENTS WITH CARDIOVASCULAR DISEASE}

The convenience and efficacy of new oral treatments for ED have led to a significant increase in demand for treatment. With the use of these new oral agents has also come a concern about the risks of sexual activity by cardiac patients, ${ }^{20-22}$ so that family practitioners may be reluctant to prescribe these medications to patients considered to be at risk of cardiovascular disease. Thus, the Princeton Consensus Panel produced specific guidelines for the management of $\mathrm{ED}$ in the cardiovascular patient. ${ }^{23}$

The rationale of these guidelines lies in the principle that sexual activity poses a small but definite risk of a cardiac event for the patient with cardiac disease during and immediately after sexual activity. A 50 year old healthy man has a baseline annual risk of myocardial infarction of $1 \%$. As a consequence of sexual activity by a healthy man, the risk increases to $1.01 \%$ but it increases to $1.1 \%$ in a man with previously documented coronary artery disease..$^{23}$ In addition, the absolute risk for healthy men to have a cardiac event from normal daily life is one chance in a million. This risk increases to two chances per million following sexual activity and lasts for a two hour period. Men with coronary artery disease have a 10 -fold increased risk, which translates to 20 chances in a million. ${ }^{24}$ Hence, a small but definite risk of a cardiac event exists for the patient with a history of cardiovascular disease who is resuming sexual activity.
During sexual intercourse the average maximal heart rate is $120-130$ beats/minute with a systolic blood pressure increase to $150-180 \mathrm{~mm} \mathrm{Hg}$. This peak lasts for only 3-5 minutes of the average $5-15$ minute duration of sexual activity. ${ }^{25}$ This equates to 5-6 metabolic equivalents or 4 minutes of the Bruce treadmill protocol ( $10 \%$ grade, $2.7 \mathrm{~km} / \mathrm{h}$ ). To resume sexual activity, patients need to be capable of sustaining this physiological demand without any cardiovascular symptoms. The Princeton guidelines stratify patients into cardiovascular risk groups according to cardiovascular symptoms and physiological reserve (table 1). ${ }^{26}$ The low risk group are those for whom sexual activity is not a significant cardiovascular risk and who meet the requirements of physiological reserve to resume sexual activity. The high risk patient is one in whom cardiovascular symptoms are limiting to the extent that further cardiovascular evaluation and investigation are considered necessary. Sexual activity and the management of ED should be deferred in these patients until the patient's cardiovascular condition has been fully evaluated, treated, and stabilised. A third group has been identified as being at intermediate risk and these patients must have ED management deferred until further cardiovascular evaluation can restratify them into either the low or high risk groups.

These guidelines incorporate clinically useful methods for the assessment of cardiac risk associated with sexual activity and for the management of sexual dysfunction among patients with known cardiovascular risk factors or diseases. They are already in use in the clinical setting and are extremely valuable in managing ED in cardiac patients.

\section{CONCLUSION}

ED is a common condition particularly affecting men with underlying vascular disease. The reluctance of men to discuss this sensitive issue leads to an impaired quality of life. In addition, this reluctance may hinder the opportunity to diagnose occult cardiovascular disease and hence prevent significant morbidity and sometimes mortality. Endothelial dysfunction appears to be the link between these conditions and increasing awareness of this association should encourage men to discuss their ED with medical practitioners.

The Princeton guidelines have addressed the issue of the management of ED in men with established cardiovascular disease. Cardiovascular risk stratification is the mainstay of 
these guidelines and allows the identification of intermediate to high risk patients who may continue to have uncontrolled cardiovascular disease. Cardiovascular disease control must be the priority in these groups over ED management. Low risk patients are also identified and in these patients the management of ED can be safe and effective.

\section{Authors' affiliations}

H Solomon, J W Man, G Jackson, Department of Cardiology, 6th Floor, East Wing, St Thomas' Hospital, Lambeth Palace Road, London SEI 7EH, UK

\section{REFERENCES}

1 Anon. Impotence. NIH Consens Statement 1992;10(4): 1-33.

2 Ayta IA, McKinlay JB, Krane RJ. The likely worldwide increase in erectile dysfunction between 1995 and 2025 and some possible policy consequences. BJU Int 1999:84:50-6.

3 Feldman HA, Goldstein I, Hatzichristou DG, et al. Impotence and its medical and psychosocial correlates: results of the Massachusetts male aging study. J Urol 1994;151:54-61.

4 Jonler M, Moon T, Brannan W, et al. The effect of age, ethnicity and geographical location on impotence and quality of life. Br J Urol 1995;75:651-5

5 Willke RJ, Glick HA, McCarron TJ, et al. Quality of life effects of alprostadil therapy for erectile dysfunction. J Urol 1997;157:2124-8.

6 Lue TF. Erectile dysfunction. N Engl J Med 2000;342:1802-13.

7 Carrier S, Brock G, Kour NW, et al. Pathophysiology of erectile dysfunction. Urology 1993;42:468-81

8 Billups K, Friedrich S. Assessment of fasting lipid panels and Doppler ultrasound testing in men presenting with erectile dysfunction and no other problems. J Urol 2000;163(4):147.

9 Kaiser FE, Viosca SP, Morley JE, et al. Impotence and aging: clinical and hormonal factors. J Am Geriatr Soc 1988;36:511-9.

10 Bortolotti A, Parazzini F, Colli E, et al. The epidemiology of erectile dysfunction and its risk factors. Int J Androl 1997;20:323-34.
11 De Angelis L, Marfella MA, Siniscalchi M, et al. Erectile and endothelial dysfunction in type II diabetes: a possible link. Diabetologia 2001;44:1155-60.

12 Junemann KP, Aufenanger J, Konrad T, et al. The effect of impaired lipid metabolism on the smooth muscle cells of rabbits. Urol Res 1991;19:271-5

13 Anderson M, Nicholson B, Lovie E, et al. An analysis of vasculogenic erectile dysfunction as a potential predictor of occult cardiac disease. $J$ Urol 1998;159(suppl 5):118.

14 Pritzker M. The penile stress test: a window to the hearts of man? Circulation 1999;100(suppl I):I-711.

15 Greenstein A, Chen J, Miller H, et al. Does severity of ischemic coronary disease correlate with erectile function? Int J Impot Res 1997;9:123-6.

16 Brock GB, Lue TF. Drug-induced male sexual dysfunction: an update. Drug Saf 1993;8:414-26.

17 Jackson G. Simvastatin and impotence. BM 1997;315:31.

18 Jensen J, Lendorf A, Stimpel $H$, et al. The prevalence and etiology of impotence in 101 male hypertensive outpatients. Am J Hypertens 1999; 12:271-5.

19 Kostis JB, Padma-Nathan H, Rosen RC. A symposium: sexual activity and cardiac risk: the Princeton conference. Am J Cardiol 2000;86: 1F-68F

20 Kloner RA. Cardiovascular risk and sildenafil. Am J Cardiol 2000;86:57F-61F.

21 Chew KK, Stuckey BG, Thompson PL. Erectile dysfunction, sildenafil and cardiovascular risk. Med J Aust 2000;172:279-83.

22 Cheitlin MD, Hutter AM Jr, Brindis RG, et al. Use of sildenafil (Viagra) in patients with cardiovascular disease. Technology and Practice Executive Committee. Circulation 1999;99:168-77.

23 DeBusk R, Drory Y, Goldstein I, et al. Management of sexual dysfunction in patients with cardiovascular disease: recommendations of the Princeton Consensus Panel. Am J Cardiol 2000;86:175-81.

24 Muller JE. Sexual activity as a trigger for cardiovascular events: what is the risk? Am J Cardiol 1999;84:2N-5N.

25 Jackson G. Sexual intercourse and stable angina pectoris. Am J Cardiol 2000;86:35F-7F.

26 Jackson G, Betteridge J, Dean J, et al. A systematic approach to erectile dysfunction in the cardiovascular patient: a consensus statement. Int J Clin Pract 1999;53:445-51.

\section{ELECTRONIC PAGES}

\section{eHEART: www.heartinl.com}

jeris

he following electronic only articles are published in conjunction with this issue of Heart.

\section{Takayasu's arteritis: management of left main stem stenosis \\ I S Malik, O Harare, A AL-Nahhas, K Beatt, J Mason}

Takayasu arteritis is a chronic vasculitis involving the aorta and its main branches, the pulmonary arteries, and the coronary tree, and needs to be considered in a young patient with angina, in particular when pulses are absent. This case illustrates the limitations of exercise testing in diagnosing the extent of coronary artery disease and the risks associated with coronary angiography in patients with inflammatory disease in the left main stem coronary artery. It also highlights the novel use of non-invasive scanning with positron emission tomography using 18-fluorodeoxyglucose in assessing remission from this disease. Revascularisation was performed with percutaneous transluminal coronary angioplasty and stenting as an emergency procedure, but treatment of the restenosis with directional atherectomy was based on a review of the available literature. The lymphocytic alveolitis seen in this patient has not been previously described in Takayasu's disease.

(Heart 2003;89:e9) www.heartjnl.com/cgi/content/full/89/ 3/e9
Artefact mimicking tachycardia during magnetic resonance
imaging in a patient with an implantable loop recorder J R Gimbel, B L Wilkoff

An implantable loop recorder (ILR) was implanted in a 45 year old man with recurrent syncope. A subsequent episode of injurious syncope led to performance of a cranial and shoulder magnetic resonance imaging (MRI). An artefact mimicking both wide and narrow complex tachycardias was recorded by the ILR during the shoulder MRI but not the cranial MRI. Caution should be used when interpreting the ECGs of ILRs in patients who have undergone MRI.

(Heart 2003;89:e10) www.heartjnl.com/cgi/content/full/89/ 3/e10

Unexplained recurrent pericardial effusion: a lethal warning? C H Lee, G S W Chan, W M Chan

A case of a 37 year old man with cardiac angiosarcoma causing recurrent pericardial effusion, who eventually died of cardiac rupture, is presented. The diagnosis was not established until the postmortem examination despite echocardiography, pericardiocentesis, and pericardial biopsy investigations. There is neither a specific manifestation that enables early recognition nor well proven effective treatment against this disease. Accordingly, the prognosis of cardiac angiosarcoma remains grave. A high index of suspicion is recommended in patients who present with unexplained pericardial effusion.

(Heart 2003;89:ell) www.heartjnl.com/cgi/content/full/89/ $3 / \mathrm{e} 11$ 